\section{Morphology and Meiotic Behavior of Three Dendrobium Amphidiploids and Their Diploid Counterparts}

\author{
James McConnell ${ }^{1}$ and H. Kamemoto ${ }^{2}$ \\ Department of Horticulture, University of Hawaii, Honolulu, HI 96822 \\ Additional index words. cut flowers, cytology, Dendrobium, ploidy
}

\begin{abstract}
Floral characteristics, meiotic behavior, and sporad formation were compared in three Dendrobium tetraploids (amphidiploids) and their diploid counterparts. Amphidiploid flowers were larger than those of diploids. Diploid meiotic behavior varied; mean configurations at Metaphase I ranged from 14.3 bivalents and 9.4 univalents to 18.9 bivalents and 0.2 univalents. In amphidiploids, nearly all cells had 38 bivalents. Sporad formation also varied; diploids had $36 \%$ to $70 \%$ tetrads and amphidiploids had $97 \%$ to $100 \%$ tetrads. Preferential pairing and small chromosome size may promote bivalent formation in amphidiploids.
\end{abstract}

Dendrobium is a large and diverse Orchidaceae genus with $>1000$ species in 41 sections (Schlecter, 1982).ManyDendrobium cultivars grown for cut-flower production have been derived from intersectional crosses involving the Phalaenanthe and Ceratobium (Spatulata) sections. Phalaenanthe species generally have large full flowers but poor keeping quality, while Ceratobium species generally have small individual flowers and flower profusely in fall or spring. Intersectional hybrids have many intermediate flowers, flower throughout the year, and have good keeping quality, all desirable characteristics of cut-flower cultivars (Kamemoto, 1976, 1980; Kamemoto and Wilfret, 1971).

Diploid intersectional Phalaenanthe and Ceratobium hybrids show a high degree of chromosomal homology (Kamemoto, 1980); however, they usually are of low fertility and, thus, may be dead-ends in breeding. Chromosome doubling generally restores fertility. The resulting tetraploids (amphidiploids) often exhibit better characteristics than their diploid counterparts and have been used to develop commercial cut-flower cultivars (Kamemoto, 1976, 1980; Kamemoto and Wilfret, 1971).

The objective of this study was to compare the morphological characteristics and observe the meiotic behavior of three Dendrobium amphidiploids and their respective diploid counterparts. Two of these amphidiploids have been used as parents to produce seed-propagated amphidiploid cultivars (Kamemoto, 1985). Selfed progeny of the three amphidip-

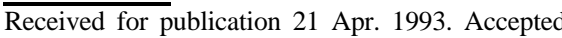
for publication 3 May 1993. Journal series no. 3784 of the Hawaii Institute of Tropical Agriculture and Human Resources. The cost of publishing this paper was defrayed in part by the payment of page charges. Under postal regulations, this paper therefore must be hereby marked advertisement solely to indicate this fact.

'Associate Professor. Current address: College of Agriculture and Life Sciences, Univ. of Guam Mangilao, Guam 96923.

${ }^{2}$ Emeritus Professor of Horticulture. loids were investigated to correlate meiotic behavior with the transmission of characteristics to their offspring.

We examined the morphological characteristics, meiosis, and sporad formation of the following three sets of diploid hybrid selections and their amphidiploid counterparts: 1) Dendrobium $\times$ Neo Hawaii Y972-2N vs. Dendrobium $\times$ Neo Hawaii Y972-4N, 2) Dendrobium $\times$ Jaquelyn Thomas 0580-3-2N vs. Jaquelyn Thomas 0580-3-4N, and 3) Dendrobium $\times$ Jaquelyn Thomas 0580-8-2N vs. Jaquelyn Thomas 0580-8-4N.

The diploid hybrids involved Phalaenanthe and Ceratobium species. Dendrobium $\times$ Neo Hawaii Y972-2N is an individual of the hybrid $D$. phalaenopsis (Phalaenanthe) $\times D$. grantii (Ceratobium). Dendrobium $\times$ Jaquelyn Thomas 0580-3-2N and Dendrobium $\times$ Jaquelyn Thomas 0580-8-2N are diploid individuals of a D. phalaenopsis $\times D$. gouldii (Ceratobium) hybrid. The respective amphidiploids originated spontaneously in tissue culture.

Morphological characteristics. Morphological characteristics were measured on the three amphidiploids and their diploid counterparts. Ten measurements each were collected for flower size, petal width and length, sepal length, and pedicel length. Flower size was measured with a template consisting of a series of circles in $0.6-\mathrm{cm}$ increments. Measuring flower size this way determined the natural flower span. Comparing the natural flower span with the petal and sepal length gives an estimate of the degree of curling or reflexing of the petals and sepals. Eighteen plants of selfed amphidiploid progeny -Dendrobium $\times$ Neo Hawaii Y972-4N, Dendrobium $\times$ Jaquelyn Thomas 0580-3-4N, and Dendrobium $\times$ Jaquelyn Thomas O580-8-4N were measured to determine the degree of variation within progeny. Mean values, standard error, and coefficient of variation (cv) were calculated for each characteristic.

Cytology. Flowerbuds were sampled when 10 to $13 \mathrm{~mm}$ long, the stage at which meiotic divisions occur in the microsporocytes. The pollinia were removed and fixed for 1 day at $22 \mathrm{C}$ in a modified Carnoy's solution (mixture of 95\% 1 ethanol : 1 chloroform : 2 glacial acetic acid). The tissue was hydrolyzed in $45 \%$ acetic acid for $3 \mathrm{~min}$ and macerated in $1 \%$ aceto-orcein, and a cover slip was applied. Rattenbury's fluid (mixture of 45\% 10 acetic acid : 1 glycerine) was applied to the side of the cover slip to destain the cytoplasm and make the slide semipermanent (Tsuchiya and Nakamura, 1979).

Slides were observed under a $\times 100$ objective with normal and phase-contrast lighting. At Metaphase I, univalents and bivalents were counted in 25 cells/plant and the frequency of sporad formation was recorded in 100 sporads. Plant chromosome numbers were determined by counting the chromosomes in root tips using the method of Kamemoto et al. (1964).

Morphological characteristics. The three amphidiploid dendrobiums were larger than their corresponding diploids for all floral characteristics (Table 1). Also, petals appeared less reflexed and curled in the amphidiploids than in the diploids. The increase in ploidy from diploidy to amphidiploidy seems to have produced larger, less-reflexed flowers in the three cases studied. The most significant changes were increased flower size, petal width, and sepal length.

Cytology. Somatic chromosome counts of root tips confirmed that diploid plants had 38 chromosomes and the amphidiploids had 76. The meiotic chromosomes of the diploids exhibited various degrees of bivalent formation at Metaphase I. The mean configurations at this stage were 14.3 bivalents and 9.4 univalents in Jaquelyn Thomas O580-3-2N, 17.7 bivalents and 2.6 univalents in Jaquelyn Thomas 0580-8-2N (Fig. 1), and 18.9 bivalents and 0.2 univalents in Neo Hawaii Y972-2N (Table 2). Sporad formation varied considerably in diploids (Fig. 3, Table 3). Neo Hawaii Y972-2N produced $70 \%$ tetrads and $30 \%$ dy-

Table 1. Mean values of various floral characteristics of diploid and amphidiploid Dendrobium $\times$ Jaquelyn Thomas O580-3, Dendrobium $\times$ Jaquelyn Thomas O580-8, and Dendrobium $\times$ Neo Hawaii Y972.

\begin{tabular}{lccccc}
\hline & \multicolumn{5}{c}{ Mean \pm sD } \\
\cline { 2 - 6 } & \multicolumn{5}{c}{ Floral characteristic (mm) } \\
\cline { 2 - 6 } Dendrobium & $\begin{array}{c}\text { Flower } \\
\text { diam }\end{array}$ & $\begin{array}{c}\text { Petal } \\
\text { width }\end{array}$ & $\begin{array}{c}\text { Petal } \\
\text { length }\end{array}$ & $\begin{array}{c}\text { Sepal } \\
\text { length }\end{array}$ & $\begin{array}{c}\text { Pedicel } \\
\text { length }\end{array}$ \\
\hline Jaquelyn Thomas O580-3-2N & $57.2 \pm 4.0$ & $13.5 \pm 0.7$ & $38.1 \pm 1.8$ & $34.4 \pm 1.1$ & $44.8 \pm 3.3$ \\
Jaquelyn Thomas O580-3-4N & $63.5 \pm 2.5$ & $15.1 \pm 0.6$ & $42.6 \pm 1.2$ & $37.4 \pm 1.2$ & $46.4 \pm 3.1$ \\
Jaquelyn Thomas O580-8-2N & $63.5 \pm 2.1$ & $12.7 \pm 0.7$ & $36.3 \pm 0.9$ & $38.7 \pm 1.1$ & $52.8 \pm 2.6$ \\
Jaquelyn Thomas O580-8-4N & $82.6 \pm 2.5$ & $15.9 \pm 0.5$ & $44.2 \pm 0.8$ & $42.7 \pm 0.8$ & $60.3 \pm 3.5$ \\
Neo Hawaii Y972-2N & $57.2 \pm 2.6$ & $13.5 \pm 0.8$ & $36.2 \pm 1.2$ & $31.8 \pm 0.7$ & $39.1 \pm 1.9$ \\
Neo Hawaii Y972-4N & $63.5 \pm 3.0$ & $16.7 \pm 1.0$ & $36.4 \pm 1.1$ & $35.8 \pm 0.9$ & $43.2 \pm 3.0$ \\
\hline
\end{tabular}




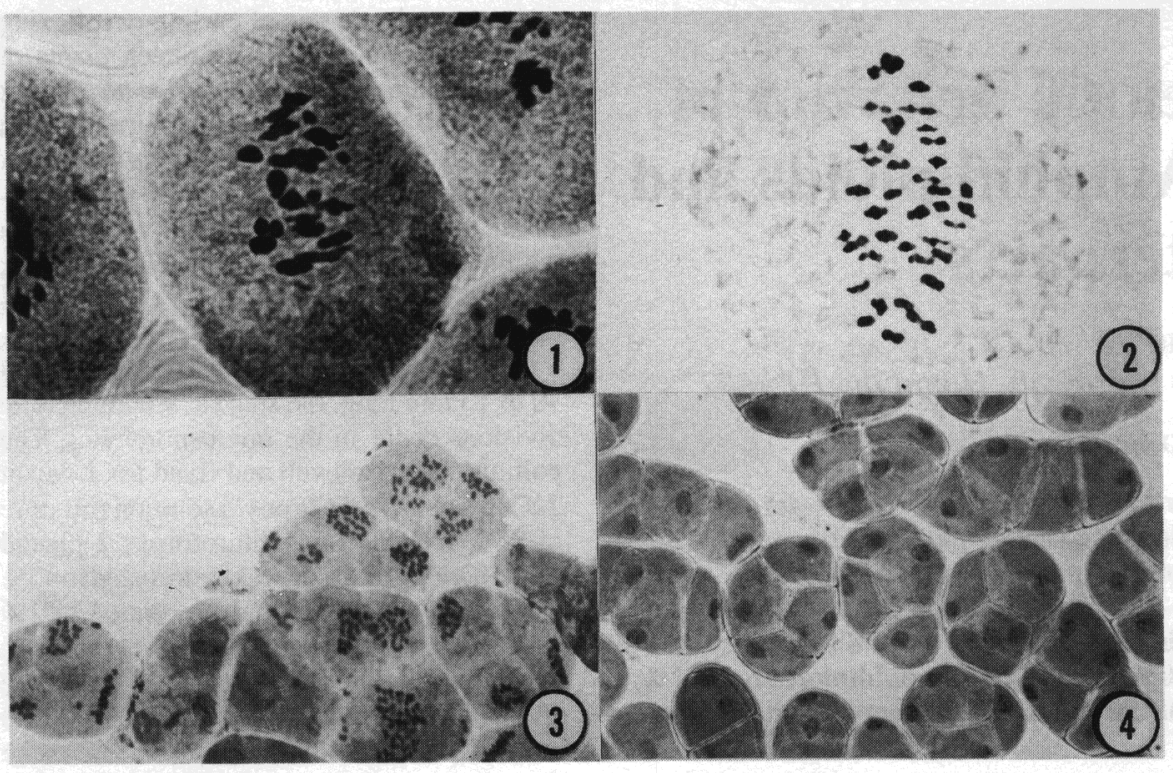

Figs. 1-4. Meiosis and sporad formation in Dendrobium $\times$ Jaquelyn Thomas O580-8-2N and Jaquelyn Thomas O580-8-4N. (1) Jaquelyn Thomas O580-8-2N showing 18 II and 2 I, (2) Jaquelyn Thomas O580-8-4N showing $38 \mathrm{II}$, (3) Jaquelyn Thomas O580-8-2N showing irregularities in sporad formation, and (4) Jaquelyn Thomas O580-8-4N showing regular microspore tetrads.

Table 2. Mean chromosome configurations at Metaphase I of meiosis in diploid and amphidiploid Dendrobium x Jaquelyn Thomas 0580-3, Dendrobium $\mathrm{x}$ Jaquelyn Thomas O580-8, and Dendrobium $\times$ Neo Hawaii Y972.

\begin{tabular}{lc}
\hline \hline Dendrobium & $\begin{array}{c}\text { Mean } \\
\text { configuration/ } \\
\text { PMC }^{z}\end{array}$ \\
\hline Jaquelyn Thomas O580-3-2N & $14.3 \mathrm{II}+9.4 \mathrm{I}$ \\
Jaquelyn Thomas O580-3-4N & $38.0 \mathrm{II}$ \\
Jaquelyn Thomas O580-8-2N & $17.7 \mathrm{II}+2.6 \mathrm{I}$ \\
Jaquelyn Thomas O580-8-4N & $37.8 \mathrm{II}+0.4 \mathrm{I}$ \\
Neo Hawaii Y972-2N & $18.9 \mathrm{II}+0.2 \mathrm{I}$ \\
Neo Hawaii Y972-4N & $38.0 \mathrm{II}$ \\
\hline
\end{tabular}

2PMC $=$ pollen mother cell; mean of 25 observations. ads. Jaquelyn Thomas O580-3-2N and Jaquelyn Thomas 0580-8-2N produced fewer tetrads - $42 \%$ and $36 \%$, respectively-and a large proportion of the remaining sporads were dyads. Frequently, 19 bivalents were observed in Neo Hawaii Y972-2N pollen mother cells (PMCs). Like meiosis, sporad formation was more irregular in Jaquelyn Thomas 0580-2N than in Neo Hawaii Y972-2N. Neo Hawaii Y972-2N produced only tetrads and dyads, while Jaquelyn Thomas 0580-2N produced a range of sporad configurations. Microcytes were observed in the individuals that had a high univalent frequency during Metaphase I.

Table 3. Sporad formation in diploid and amphidiploid Dendrobium $\times$ Jaquelyn Thomas O580-3, Dendrobium $\times$ Jaquelyn Thomas O580-8, and Dendrobium $\times$ Neo Hawaii Y972.

\begin{tabular}{lccccc}
\hline & \multicolumn{5}{c}{ No. sporads observed } \\
\cline { 2 - 5 } Dendrobium & Tetrads & $\begin{array}{c}\text { Tetrads } \\
\text { + microcytes }\end{array}$ & Dyads & $\begin{array}{c}\text { Dyads } \\
\text { + microcytes }\end{array}$ & Monads \\
\hline Neo Hawaii Y972-2N & 70 & 3 & 30 & \\
Neo Hawaii Y972-4N & 97 & 3 & 52 & 2 & 1 \\
Jaquelyn Thomas O580-3-2N & 42 & 100 & & 48 & 9 \\
Jaquelyn Thomas O580-3-4N & 36 & 6 & & 1 \\
Jaquelyn Thomas O580-8-2N & 99 & 1 & & \\
Jaquelyn Thomas O580-8-4N & & & &
\end{tabular}

${ }^{2}$ Total sporads $=100$ for all cultivars.

Table 4. Mean values of inflorescences and floral characters for selfed progeny of amphidiploid Dendrobium x Jaquelyn Thomas O580-3-4N, Dendrobium $x$ Jaquelyn Thomas O580-8-4N, and Dendrobium $\times$ Neo Hawaii Y $972-4 N$.

\begin{tabular}{|c|c|c|c|c|c|c|}
\hline \multirow[b]{3}{*}{ Characteristics } & \multicolumn{6}{|c|}{ Selfed progenies } \\
\hline & \multicolumn{2}{|c|}{$\begin{array}{c}\text { Jaquelyn Thomas } \\
\text { O580-3-4N }\end{array}$} & \multicolumn{2}{|c|}{$\begin{array}{c}\text { Jaquelyn Thomas } \\
\text { O580-8-4N }\end{array}$} & \multicolumn{2}{|c|}{$\begin{array}{l}\text { Neo Hawaii } \\
\text { Y972-4N }\end{array}$} \\
\hline & Mean \pm sD & $\operatorname{cv}(\%)$ & Mean \pm SD & $\mathrm{Cv}(\%)$ & Mean \pm sD & $\mathrm{Cv}(\%)$ \\
\hline Flowers/raceme (no.) & $13.6 \pm 0.6$ & 20.1 & $18.4 \pm 0.7$ & 16.7 & $14.9 \pm 0.4$ & 12.9 \\
\hline Scape length $(\mathrm{cm})$ & $20.0 \pm 0.9$ & 20.7 & $22.9 \pm 0.8$ & 14.4 & $19.1 \pm 0.4$ & 10.3 \\
\hline Raceme length $(\mathrm{cm})$ & $45.9 \pm 1.8$ & 17.5 & $60.4 \pm 1.8$ & 13.2 & $53.5 \pm 2.4$ & 20.4 \\
\hline Flower diam (mm) & $61.4 \pm 2.3$ & 16.5 & $79.0 \pm 1.8$ & 6.3 & $63.5 \pm 0.8$ & 5.7 \\
\hline Petal length (mm) & $38.3 \pm 0.4$ & 5.0 & $43.0 \pm 0.7$ & 6.5 & $34.8 \pm 0.5$ & 5.9 \\
\hline Petal width $(\mathrm{mm})$ & $16.0 \pm 0.3$ & 8.5 & $16.2 \pm 0.1$ & 3.4 & $16.9 \pm 0.2$ & 4.2 \\
\hline Pedicel length (mm) & $49.0 \pm 1.2$ & 10.4 & $57.4 \pm 1.0$ & 7.2 & $42.6 \pm 0.7$ & 6.9 \\
\hline
\end{tabular}

Plants showing irregular sporad formation would be expected to have reduced fertility.

Meiotic behavior in the three amphidiploids was regular (Figs. 2 and 4; Tables 2 and 3 ), unlike that in the diploids. Complete bivalent pairing was observed at Metaphase I in Neo Hawaii Y972-4N and Jaquelyn Thomas 05803-4N PMCs. The mean configuration for Jaquelyn Thomas O580-8-4N was 37.8 bivalents and 0.4 univalents. Sporad formation also was regular, with a high percentage of tetrads: $97 \%$ in Neo Hawaii Y972-4N, 100\% in Jaquelyn Thomas 0580-3-4N, and 99\% in Jaquelyn Thomas 0580-8-4N.

The preponderance of bivalents at Metaphase I and tetrad formation at the end of meiosis in the amphidiploids in spite of high pairing between the genomes in the diploids suggest that some mechanism prevents multivalent formation in the amphidiploids. The lack of multivalent associations may be due to small chromosome size. Polysomic species with short chromosomes may have the potential for only one chiasma per chromosome, a condition preventing multivalent formation (Sanford, 1983).

While multivalents were absent in the three amphidiploids, they were present in a Jaquelyn Thomas 0580-3-4N S plant at a low frequency. There were some loose bivalent associations, which possibly indicated intergenomal pairing. In addition, the presence of univalents in Jaquelyn Thomas O580-8-4N also may be a result of intergenomal pairing. The chromosomes may have paired during prophase but formed only loose associations and separated at Metaphase I. Preferential pairing also may contribute to the lack of multivalent formation. Occasional multivalents have been reported in plants exhibiting preferential pairing (Byrne and Jelenkovic, 1976); this observation may account for the cytological deviation seen in the Jaquelyn Thomas 0580-3-4N S, plant. The chromosome behavior observed indicates the possibility of some intergenomal pairing.

Uniformity of selfed progeny. For the three $\mathrm{S}_{1}$ amphidiploid progeny, the cv for the inflorescence characteristics-number of flowers perraceme, scape length, and raceme lengthwas high (Table 4), a result possibly suggesting variation among the offspring. However, these characteristics are variable even among clones, and, therefore, are not the best indicators of genetic variance. In contrast, the $\mathrm{cv}$ for floral characteristics-flower size, petal length and width, and pedicel length-were low, except for the flower size of Jaquelyn Thomas 0580-3-4N progeny. This high cv of 16.5 was due in part to a high degree of petal reflexing, which gave a smaller reading for flower size.

The floral and vegetative characteristics of all three selfed progeny appeared highly uniform. Also, few differences could be detected readily between the parents and their selfed progeny.

The uniformity of characteristics in the $S_{1}$ progeny suggests that little recombination occurred between the Phalaenanthe and Ceratobium genomes, despite the high degree of chromosome pairing in diploid intersectional 
hybrids, presumably because of within-genome pairing. This uniformity as a result of preferential pairing has allowed the development of seed-propagated amphidiploid cutflower cultivars (Kamemoto, 1985). However, even with preferential pairing, multivalents and univalents are produced occasionally, and plants with large, white flowers have been developed by selecting and inbreeding an amphidiploid (Bobisud and Kamemoto, 1981).

\section{Literature Cited}

Bobisud, C.A. and H. Kamemoto. 1981. Selection and inbreeding in amphidiploid Dendrobium (Orchidaceae). J. Amer. Soc. Hort. Sci. 107:1024-1027.
Byrne, D. and G. Jelenkovic. 1976. Cytological diploidization in the cultivated octoploid strawberry Fragaria $\times$ ananassa. Can. J. Genet. Cytol. 18(4):653-659.

Kamemoto, H. 1976. Cytogenetics and breeding of dendrobium orchids. J. Soc. Advancement Breeding Res. Asia \& Oceania 8(1):17-27.

Kamemoto, H. 1980. Breeding dendrobiums for commercial cut flower production, p. 96-107. In: K.G. Singh (ed.). Proc. 3rd Assn. Southeast Asian Nations Orchid Congr., Ministry Agr., Malaysia.

Kamemoto, H. 1985. Seed-propagated amphidiploid dendrobium cultivars. Ho\&Science 20:2, 163.

Kamemoto, H., K. Shindo, and K. Kosaki. 1964. Chromosome homology in the Cerutobium, Phalaenanthe, and Latourea sections of the genus Dendrobium. Pacific Sci. 18(1):104-115.

Kamemoto, H. and G.J. Wilfret. 1971. Genome breeding in Dendrobium, p. 245-248. In: M.J.G. Corrigan (ed.). Proc. 6th World Orchid Conf., Sydney, Australia.

Sanford, J.C. 1983. Ploidy manipulations, p. 100123. In: J.N. Moore and J. Janick (eds.). Methods in fruit breeding. Purdue Univ. Press, West Lafayette, Ind.

Schlecter, R. R.S. Rogers, H.J. Katz, and J.T. Simmons (translators). D.F. Blaxell (ed.). 1982. The Orchidaceae of German New Guinea. Austral. Orchid Foundation, Melbourne. p. 508747.

Tsuchiya, T. and C. Nakamura. 1979. Aceto-carmine squash method for observing sugar beet Beta vulgar-is chromosomes. Euphytica 28(2):249-256. 